\title{
Investigación
}

\section{El software, un bien intangible con naturaleza propia}

\author{
Software, an intangible asset \\ with its own nature
}

\author{
Olga Lucía Troncoso Estrada*
}

Recepción: 06/08/2020 • Aprobación: 02/09/2020 • Publicación: 01/12/2020

Para citar este artículo

Troncoso Estrada, O. L. (2020). El software, un bien intangible con naturaleza propia. Dos mil tres mil, 22, e251.

https://doi.org/10.35707/dostresmil/22251
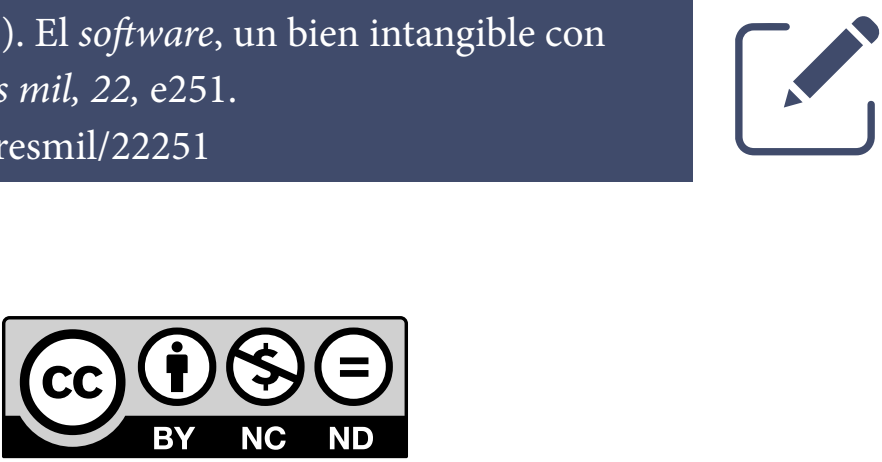

"Grupo de investigación Zoon Politikon, Facultad de Derecho y Ciencias Políticas, Universidad de Ibagué, Colombia. ORCID: 00000001-8609-4076. Correo electrónico: olga.troncoso@unibague.edu.co 
Resumen. Con la invención de la computadora y el internet a mediados del siglo $\mathrm{xx}$, fue necesario enfrentar las dificultades que podían presentarse para la protección de la propiedad intelectual en este nuevo escenario, que lejos de quedar resueltas se vuelven más complejas en la medida que los avances tecnológicos ofrecen nuevos retos. Surgen, así mismo, nuevos bienes inmateriales, como lo es el software, el que jurídicamente se ha asimilado a una obra literaria y en consecuencia se protege por las normas autorales que, no obstante, ha generado múltiples discusiones doctrinales, sosteniéndose por cierto sector que este bien es susceptible de ser patentado en caso de que se reúnan los presupuestos para este tipo de reconocimiento. Otros, defienden la necesidad de una normativa especial que contemple las condiciones especiales de este bien y, ante todo, se vislumbra la necesidad de un organismo especial, dotado de los recursos técnicos necesarios, que se encargue del registro y verificación de los requisitos para su protección, dado que se trata de un bien intangible con unas características particulares que demanda un tratamiento especial.

Abstract. With the invention of the computer and the internet in the mid-20th century, it was necessary to face the difficulties that could arise for the protection of intellectual property in this new scenario, which, far from being resolved, become more complex as technological breakthroughs offer new challenges. Likewise, new intangible assets emerge, such as software, which has been legally assimilated to a literary work and consequently is protected by copyright laws that, however, has generated multiple doctrinal discussions, being supported by a certain sector that this asset is likely to be patented in case budgets for this type of validation are met. Others defend the need for a specific regulation that contemplates special conditions of this asset and, above all, the need for a special body, provided with the necessary technical resources, which might be responsible for the registration and verification of the requirements for its protection, given that it is an intangible asset with particular characteristics that requires special treatment.

Palabras claves

Autor, obra, software, patente, doble protección.

Key words

Author, work, software, patent, double protection. 


\section{Introducción}

Si bien el derecho como ciencia jurídica encuentra sus orígenes mucho antes de la era cristiana, no sucede igual con la concepción de propiedad sobre bienes inmateriales, la que solo vino a delimitarse ya bien entrada la Edad Media y consolidarse a finales del siglo xix con la suscripción del Convenio de Berna y el Convenio de París. A partir de entonces se ha estructurado un esquema de normas homogéneo, para dar protección a la propiedad intelectual en el que se consideró su mayor desafío, el fenómeno globalizador.

En efecto, si bien la actividad creativa es connatural a la naturaleza humana, en los tiempos antiguos e incluso en la llamada Edad Media no fue necesario regular jurídicamente las relaciones que pudieran surgir de este tipo de obras, puesto que las normas existentes para ese momento, permitían definir los derechos que surgían de la misma.

La situación cambia con adelantos como la invención de la imprenta y el fonógrafo, que llevaron a la distribución masiva de obras impresas y grabadas, obligándose a que los diferentes Estados expidieran normas que garantizaran su protección. Esta situación se mantiene, guardadas proporciones, puesto que nuevos adelantos tecnológicos han puesto en tela de juicio las normas existentes, forzando una interpretación más amplia e incluso su modificación, con miras a abarcar obras que en principio eran impensables para la mente humana.

Así, por ejemplo, la concepción tradicional de autor que se restringía dentro del sistema latino a la persona natural, no es suficiente para explicar la autoría de obras creadas por las llamadas "inteligencias artificiales". Igualmente sucede con obras creadas en ejecución de un software o programa de ordenador.

Sobre estos últimos, hay una opinión mundial generalizada, en torno a que debe ser protegido asimilándose a una obra literaria, dado que se materializa a través de un lenguaje de programación. Pero lo anterior no permite dilucidar el problema jurídico que surge cuando, quien obtiene una licencia para ejecutar un software, en desarrollo del mismo da lugar a la creación de una obra susceptible de ser protegida.

Igualmente, se afirma por algún sector de la doctrina, que la protección del software por las normas propias del derecho de autor no es integral, puesto que algunos de los componentes del mismo no encajan dentro del concepto de obra protegida. De ahí que se afirme que nada impide que en caso de que el software reúna los presupuestos de novedad, altura inventiva y aplicación industrial, sea susceptible de ser patentado, permitiéndose de esta forma una doble protección para este tipo de bienes, bajo las normas del derecho de autor, en cuanto se refiere al código fuente y al código objeto, y bajo una patente para componentes de otra índole.

Actualmente en el sistema jurídico colombiano, se establece por la Decisión 351 de 1993, que el software es protegido por las normas propias del derecho de autor y por la Decisión 486 de 2000, que el mismo no es considerado una invención y por ende no es susceptible de ser patentado. 
No obstante, hemos sostenido en otro trabajo sobre el tema, que lo anterior implica un desconocimiento de las normas del Acuerdo sobre los Aspectos de los Derechos de Propiedad Intelectual relacionados con el Comercio (ADPIC), el cual ha sido ratificado por Colombia, y que sostiene que las patentes han de ser otorgadas sin discriminación acerca del campo tecnológico al cual pertenezcan.

En esa medida, e interpretando armónicamente los dos cuerpos normativos, consideramos que puede darse la doble protección para este tipo de bienes, pero de ser esto posible, identificamos otra problemática, relacionada con las autoridades administrativas que tienen a su cargo la valoración de los requisitos que debe reunir un bien de esta naturaleza para ser protegido.

Consideramos, y ese será el tema de la reflexión consignada en este artículo, que dada su particular naturaleza, su valoración con miras a su registro y de ser el caso, su posible patentabilidad, debe estar a cargo de un ente especializado que esté dotado además de todos los recursos técnicos requeridos para el efecto.

\section{Regulación actual del software}

A finales del siglo XIX, se suscribieron dos grandes acuerdos multilaterales tendientes a proteger debidamente los derechos que surgen de las creaciones del intelecto. Se hace referencia al Convenio de París en materia de propiedad industrial y el Convenio de Berna de 1886, para la protección de los derechos que emanan de las obras artísticas y literarias, en los que se sentaron las bases mínimas de protección que deben garantizar los países firmantes.

Estos dos grandes acuerdos conservan su vigencia, pese a las modificaciones que han surgido a través del tiempo, motivadas ante todo en la necesidad de incluir nuevos bienes objeto de protección en la medida que los adelantos tecnológicos lo han hecho necesario. Así las cosas, el Convenio de Berna ha sido enmendado en diferentes oportunidades, la última de ellas el 28 de septiembre de 1979.

Cuando a mediados del siglo xx surge el fenómeno integracionista como resultado de la globalización, se entendió que el tema de la propiedad intelectual era sensible en el intercambio comercial, por esto se incluyó dentro de los temas respecto de los cuales los países pertenecientes a los diferentes esquemas de integración, ceden competencia a fin de que sea el organismo supranacional el que legisle sobre la materia.

En el caso de la Comunidad Andina de Naciones (CAN), de la cual Colombia es país integrante, se expidió la Decisión 351 de 1993 para regular lo relacionado con los derechos de autor y derechos conexos, en la cual, siguiendo los lineamientos del Convenio de Berna, se definió la obra protegida como toda creación intelectual original de naturaleza artística, científica o literaria, susceptible de ser divulgada o reproducida en cualquier forma, para pasar luego, en el artículo 4, a enunciar las diferentes obras incluidas dentro de este concepto, enumerando en el literal 1 , los programas de ordenador. 
Así mismo, se expidió la Decisión 486 de 2000 para regular lo concerniente a la propiedad industrial, en la cual se dispuso en el artículo 15 las creaciones que no podían ser consideradas como una invención, dentro de las cuales se enlistó el programa de ordenador, lo cual implica que no puede ser cobijado con una patente.

Ahora bien, a nivel interno, el Decreto 1360 de 1989, regula lo referente a los trámites administrativos tendientes al registro del programa de ordenador como obra protegida, encargándose a la Dirección Nacional de Derechos de Autor, el llevar este registro.

Gamba Segovia y Escobar Mora explican así las razones para que se optara por las normas del derecho de autor, cuando fue necesario proteger este tipo de bienes:

Como ya se ha mencionado, la tendencia mundial es proteger el software por medio de la protección de Derechos de Autor. La razón de la exclusión obedece a que se ha considerado, en el caso de los programas de ordenador, al igual que en las restantes causales consagradas en el artículo que estudiamos, que se trata de invenciones a las que les falta el carácter técnico, es decir, que los resultados que se logran en cada uno de estos campos no producen una real contribución al estado de la técnica. (Gamba \& Escobar, 2013, p. 28).

La situación anterior que, por demás, comparten otras legislaciones en las que se contempla un tratamiento similar, es objeto de múltiples discusiones doctrinarias al considerarse que no es suficiente para garantizar los derechos de los desarrolladores de software, por esto analizaremos a continuación esta serie de cuestionamientos.

\section{Discusiones que suscita su actual sistema de protección}

\subsection{Normas obsoletas que no responden a la realidad tecnológica actual}

Como ya se dejó consignado, en materia de derechos de autor, rige la Decisión 351 de 1993, bajo la cual se regula lo referente a los programas de ordenador, y en cuanto al trámite administrativo para su registro, el Decreto 1360 de 1989, lo cual implica que este tipo de bienes se somete a normas con más de veinte años de vigencia que, por ende, no responden adecuadamente a los adelantos que se producen día a día en este campo tecnológico.

En efecto, son varias las situaciones que pueden presentarse en este campo. Así, podemos hablar de las composiciones creadas autónomamente por el ordenador en desarrollo de un software o incluso de composiciones efectuadas por la que hoy se conoce como inteligencia artificial. Sobre este tipo de obras, señala Saiz García:

Los sistemas de inteligencia artificial ya permiten a las máquinas emular el comportamiento humano y, con ello, realizar actividades que hasta ahora solo eran atribuibles a seres humanos. Entre estas capacidades típicamente humanas se encuentra la de producir resultados aparentemente creativos que, en muchas ocasiones, son fruto de largos, laboriosos y complejos procesos que una o varias empresas se encargan de financiar. En lógica contrapartida, y con fundamento en su necesidad de amortizar dicha inversión, se cuestionan la titularidad del derecho exclusivo sobre los resultados de tales proyectos. 
[...] Las cosas han cambiado mucho, no ya desde la invención de la imprenta, sino en los últimos 20 años. Los programas informáticos ya no son solo una herramienta de la que el autor se sirve como un instrumento más para crear la obra de ingenio, siempre al servicio de sus decisiones creativas, sino que son los propios sistemas de inteligencia artificial los que nacen ahora con autonomía suficiente para tomar las decisiones que tradicionalmente se asocian al ser humano en todo proceso creativo. Se conocen como redes neuronales, algoritmos de inteligencia artificial que aprenden a partir de los datos que se les proporciona (también se denomina iA robusta). (Saiz García, 2019, pp. 2-4).

En igual sentido, señala Andrés Guadamuz:

Hace mucho tiempo que los artistas robóticos participan en diversos tipos de trabajos creativos. Las computadoras han producido obras de arte rudimentarias desde los años setenta y estas iniciativas prosiguen en la actualidad. La mayoría de esas obras de arte generadas por computadora dependían en gran medida de la creatividad del programador; la máquina era a lo sumo un instrumento o una herramienta muy parecida a un pincel o un lienzo. Pero hoy en día nos encontramos inmersos en una revolución tecnológica que puede obligarnos a repensar la interacción entre las computadoras y el proceso creativo. Esta revolución está impulsada por el rápido desarrollo del software de aprendizaje automático, un subconjunto de la inteligencia artificial que produce sistemas autónomos capaces de aprender sin estar específicamente programados por el ser humano. (Guadamuz, 2017, p. 17).

Autores como Grau-Kuntz (2017), critican, no obstante, el que las normas que regulan el derecho de autor no se han adaptado a esta nueva realidad social. Dice el autor citado:

La forma de comprender este mecanismo y su transposición a la actualidad permite entender la crisis moderna que ha venido rondando al derecho de autor: las transformaciones sociales que han aparecido junto a la revolución tecnológica - o revolución informática - han hecho mella en el derecho de autor, que aún mantiene su forma tradicional, que no ha logrado reconocer la nueva realidad y, así, no está en condiciones de proporcionar buenas respuestas jurídicas a esta. Sin embargo, el análisis histórico también nos permite afirmar que el derecho siempre acaba por adaptarse a la realidad. Solo es una cuestión de tiempo. (Grau-Kuntz, 2017, p. 148).

Es claro entonces que el legislador andino se encuentra en mora de actualizar las normas que regulan el tema, y al atender a los cuestionamientos que se hablan en este artículo, sería la ocasión propicia para expedir una normativa especial, que no resulte forzada al tratar de adecuar las normas ya existentes a un bien que no responde en su totalidad a estas disposiciones.

No debe olvidarse por demás que cuando se pensó en proteger este nuevo bien inmaterial, la idea primigenia fue regularlo por una normatividad específica que atendiera a sus particulares circunstancias, pero por razones de índole económica y por facilismo administrativo, se optó por asimilarlo a una obra literaria, cuando no todos sus componentes responden a este concepto. 


\section{2. ¿Falta de protección del código objeto?}

Dentro de los elementos que pueden distinguirse en un programa de computador, se encuentra el código fuente, que son las instrucciones que el programador da a la máquina para que cumpla la función deseada, el cual se plasma en un lenguaje especializado de programación y de ahí que se asimile a una obra literaria. Pero este conjunto de instrucciones que son entendibles por los expertos en el tema, es convertido por el computador en un lenguaje binario que solo es comprensible por la máquina, que se conoce como código objeto y que es ininteligible para un ser humano.

Es esta la razón por la que se ha planteado que el código objeto no puede ser considerado como una obra literaria, ya que no puede ser entendida por el hombre y por ende quedaría por fuera de la protección bajo las normas del derecho de autor.

Se encuentran, no obstante, pronunciamientos como el de la Dirección Nacional de Derechos de Autor en Colombia, basada en el concepto de uno de sus asesores (Carrillo, 1990), según el cual, la protección es integral, es decir que cobija tanto al código fuente como al código objeto. Así lo expresa el mencionado asesor, citado por Mejía (2011):

El conjunto de símbolos o instrucciones para una máquina, plasmado en un escrito, pueden a su vez, ser transformados en un programa o código fuente, cuando dichos símbolos o instrucciones se 'escriben' en algún lenguaje de programación evolucionado. Es importante manifestar que tanto el escrito contentivo de las instrucciones, comúnmente denominado organigrama, como su correspondiente transformación en código fuente, son creaciones del ingenio y del talento humano o, en otras palabras, creaciones del espíritu tal como están definidas en el artículo 2 de la Ley 23 de 1982. En este contexto es importante aclarar que cuando se habla de organigrama, código fuente y código objeto, respecto de un software determinado, no podría afirmarse que se está hablando de tres creaciones u obras diferentes, por el contrario, solo cabe hablar de una obra, por tratarse de una creación conjunta del intelecto que se materializa a través de la utilidad que le brinda a cada usuario como resultado final. (Mejía, 2011, p. 10).

En igual sentido, Herrera Bravo, citado por Flórez Acero y Sierra Marulanda (2017), considera que el "Código Objeto es la traducción del programa fuente al lenguaje binario del sistema computacional en el cual se utilizará el programa” (p. 35).

En contraposición a lo anterior, encontramos criterios como el de Heredero, citado por Ramírez Vélez y Cano Gutiérrez (2015), quien distingue entre la naturaleza del código fuente y el código objeto de tal manera que no encajan dentro de la misma forma de protección:

Los programas responden esencialmente al concepto de invención, pero a la vez constituyen verdaderas obras [...] El programa es, en parte, invención, en la medida en que el código objeto constituye una regla técnica para la utilización de fuerzas de la naturaleza para lograr un resultado técnico. Mediante el código objeto (secuencia de instrucciones o pasos de máquina) se producen unas modificaciones de la realidad (procesos de información) que dan lugar a un resultado determinado (una información distinta). Esta clasificación no es válida, sin embargo, para el código fuente. Este 
no puede considerarse invención puesto que por sí solo no hace que las fuerzas de la naturaleza produzcan un resultado. Por ello el software es una creación del ingenio que participa de la naturaleza de la invención y de la obra: el código fuente sería una obra y el código objeto una invención. (Ramírez \& Cano, 2015, p. 15).

Así mismo, encontramos a quienes, como Preinfalk (2010), se oponen a que se contemple el código objeto como una traducción del código fuente, señalando además que no puede ser considerado como una obra protegida:

El programa fuente se expresa a través de un lenguaje de programación, considerado de alto nivel. Es el elaborado por el programador, inteligible para el ser humano, pero no para el ordenador. En razón de ello, este código puede ser alterado por quien sea conocedor en la materia, además, puede reproducir aquellas rutinas que le sean más útiles.

El programa objeto se expresa en código binario, o sea, en unos y ceros. Es el programa fuente convertido en lenguaje máquina para que pueda ser leído por el ordenador. Esta labor es realizada por unos programas llamados ensambladores, intérpretes o compiladores, de manera automática. Esta transposición de un lenguaje a otro, no la lleva a cabo una persona. Entonces, el programa traducido no es una creación humana, requisito indispensable en toda obra susceptible de ser protegida por el derecho de autor. Derivado de lo anterior, la transposición del programa de un lenguaje a otro, tampoco llevará el sello o la impronta de la personalidad del autor, ni se llevará a cabo una labor creativa en la traducción del programa. En consecuencia, el programa objeto no constituye una obra derivada, porque es el mismo programa en un lenguaje distinto. Existe identidad entre el programa elaborado en código fuente y el transformado a código máquina. Por estas razones consideramos que el programa en código objeto no es una traducción del programa fuente. (Preinfalk, 2010, pp. 122-123).

En consecuencia, vemos que existen opiniones encontradas sobre este punto en particular, lo cual nos lleva a concluir que no está claro que proteger el código objeto bajo las normas del derecho de autor como lo declaran el Acuerdo ADPIC y las Decisiones andinas, esté conforme con su verdadera naturaleza, discusión que podría obviarse al considerar el software como un bien único, susceptible de una regulación también específica.

\section{3. ¿Falta de protección de todos los componentes del software?}

Acerca de la concepción tradicional de proteger el software asimilándolo a una obra literaria, dado que se expresa a través de un lenguaje de programación, se critica que estos programas de ordenador no comprenden solo el código fuente y el código objeto que responden a este criterio de lenguaje, sino que además lo conforman otra serie de elementos funcionales (componentes de audio y video relacionados), que no corresponden estrictamente a una obra literaria y que por tanto, quedarían por fuera de la órbita de protección. 
Es oportuno traer a colación la industria de los videojuegos, cada vez más en auge, y en la que no es tan clara la idea del software como obra literaria. Sobre este tipo de creaciones, Álvarez Cabrera y Reyes Hernández señalan:

Los elementos creativos empleados para darles vida a los juegos de video son hoy en día de tal complejidad, que trabajar en su producción puede equipararse a una película de Hollywood (Greespan, Boyd, Purewal \& Datum, 2013): bandas sonoras interpretadas por orquestas, conceptos visuales, personajes y paisajes creados por diseñadores y artistas gráficos, argumentos y narrativas mucho más intrincadas que la clásica simulación de tenis de Pong, historias donde el jugador toma el papel del personaje principal teniendo la oportunidad de desarrollar su propia trama basada en sus elecciones personales, para así llegar a finales alternativos, y el elemento indispensable: un software soportado por un código informático que permite conjugar todos los elementos para lograr que el juego corra en la consola, ordenador o dispositivo móvil. (Álvarez \& Reyes, 2017, p. 157).

En efecto, se argumenta que hay ciertos componentes del software - como interfaces de sonido o de video- que en sí mismos no pueden ser catalogados como obras artísticas y por ende no podrían ser protegidos por las normas del derecho de autor. Así también lo expresan Flórez Acero y Sierra Marulanda:

Sin embargo, hay que destacar que esta amplitud en el espectro de lo que podría llegar a ser protegido en el derecho de autor como software no quiere decir que todos los elementos que hacen parte de los programas de computador o software, o que tengan que ver con este, estén protegidos también por medio del derecho de autor. Un ejemplo de ello son los videojuegos, respecto de las imágenes que estos generan en las pantallas, en razón a la operación del programa que los ejecuta: la posición dominante en la doctrina y en varias legislaciones es que estas imágenes van más allá del concepto legal de software. (Flórez \& Sierra, 2017, p. 43).

Sobre el particular, se contraargumenta, como se expuso con anterioridad, que la protección al software tiene un alcance integral; es decir, cobija todos sus componentes y no limita la misma considerando sus componentes de manera aislada.

Lo anterior, genera igualmente otra serie de inconvenientes como lo analizan Álvarez Cabrera y Reyes Hernández (2017), quienes citan a Ramos et al. (2013), al defender que los videojuegos deben ser objeto de una protección especial, ya que su protección como software no es suficiente:

Vemos entonces, cómo en el proceso de creación y desarrollo de un juego de video interviene un gran número de profesionales especializados, entre los que se encuentran el productor (que es quien supervisa la obra y el trabajo de todos los demás), los diseñadores (como los escritores, guionistas y diseñadores de interface), los artistas (que crean el aspecto visual del juego), los ingenieros de sonido (para los efectos de este tipo) y los programadores (que desarrollan el código), así como actores (de voz y movimiento), productores musicales y audiovisuales. 
[...] Es evidente, entonces, la existencia de una pluralidad de titulares de derechos de autor y conexos haciendo aportes al proceso creativo, razón por la cual pretender el registro del videojuego como una obra compacta significaría agruparlas en su calidad de titulares de derechos, con todas las implicaciones en materia de derechos patrimoniales que ello implicaría. (Álvarez y Reyes, 2017, p. 163).

Así las cosas, si bien tratándose de videojuegos, obras protegidas como software, se encuentran una serie de elementos que son objeto de protección bajo derechos de autor, no todos responden a la categoría de obras literarias.

\section{La doble protección, bajo normas del derecho de autor y bajo el régimen de las patentes}

Como lo anunciamos en un inicio, es nutrido el sector de la doctrina que aboga por que es perfectamente admisible el que se proteja el software bajo el régimen de las patentes. Incluso, legislaciones como la estadounidense admiten esta posibilidad, y en el campo europeo, la Oficina Europea de Patentes (OEP) desde hace algún tiempo viene concediendo patentes a este tipo de bienes, pese a que la normatividad vigente sobre el tema le restringe esta posibilidad, lo cual le ha originado una serie de críticas como la consignada a continuación por Arenas Correa:

Por otro lado, en el contexto europeo continental se ha resuelto el problema por medio de la Convención Europea de Patentes celebrada en Múnich en 1973, donde expresamente se advirtió el mecanismo de la patente como una forma inadecuada de protección a los programas de computadora. Pero dicha solución ha estado lejos de ser pacífica, sufriendo múltiples confrontaciones durante el último lustro, en el que, al amparo de una iniciativa holandesa, se ha pretendido obtener la aprobación de las patentes de software, o de 'invenciones en la computadora', que ha sufrido un fuerte rechazo por la comunidad europea, pero que alcanzó a gozar de tanta fuerza, que de no ser por el voto negativo polaco, pudo haberse convertido en normativa comunitaria europea antes de que se desistiera de este calificativo, basándose en el estudio contratado inicialmente por la propia Unión Europea. (Arenas Correa, 2013, p. 53).

Este autor, en otro trabajo sobre el tema, también ha admitido abiertamente esta posibilidad para el caso colombiano, argumentando la necesidad de que se armonicen las disposiciones contenidas en el artículo 27 del Acuerdo ADPIC, que expresamente señala que las patentes deben ser otorgadas sin discriminación alguna relacionada con el campo tecnológico al que pertenecen, y la Decisión 486 de 2000, que en su artículo 15 establece que el programa de ordenador no puede ser considerado una invención, y por ende elimina la posibilidad de que sea cobijado con una patente. Se dijo en aquella oportunidad que una interpretación armónica de las dos normas llevaría a entender que cuando el programa de ordenador no reúna los presupuestos mínimos para ser beneficiado con una patente, tendrá como mínimo la protección bajo las normas del derecho autoral, pero cuando la situación sea distinta, y por el contrario sea novedoso, tenga altura inventiva y una aplicación industrial, perfectamente puede ser cobijado con una patente, presentándose entonces la posibilidad de una doble protección. 
Lo anterior no deja de tener inconvenientes, si tomamos en consideración que el registro del software como obra literaria no está sujeto a ningún examen de funcionabilidad por la Dirección Nacional de Derechos de Autor, encargada de llevar el registro de este tipo de bienes, en tanto que la concesión de la patente debe hacerse por parte de la División de Nuevas Creaciones de la Superintendencia de Industria y Comercio, luego de un examen minucioso sobre el cumplimiento de los presupuestos para una protección de esta naturaleza. Serían dos visiones distintas e independientes sobre un mismo bien.

Por otra parte, existe otra serie de circunstancias que han de ser tenidas en cuenta, de pensarse en una doble protección, las que pasamos a analizar.

\section{1. ¿La protección del software bajo una patente debe descartarse por razones económicas?}

Cierto sector de la doctrina se muestra contrario a que se proteja el software bajo la figura de una patente, argumentando razones de índole económico dado el costo que tendría que asumirse, para determinar la novedad y el nivel inventivo en cada caso. Sobre el particular, Ramírez y Cano señalan:

Igualmente, se decide descartar, en principio, esta posibilidad de regulación, debido a los altos costos que impone para los interesados la obtención de una patente, así como por la cantidad de requisitos existentes para su concesión. Además, y más allá de lo anterior, al ser el tiempo de duración dispuesto para la protección, menor al de otros mecanismos, como el del derecho de autor, por ejemplo, se consideró no era la mejor opción. (Ramírez \& Cano, 2015, p.11).

Igualmente, Baptiste González expresa:

Siguiendo a Rengifo (1997), los contradictores del régimen de patentes al interior del Congreso estadounidense argumentaron que el software no debería someterse a este sistema de protección, puesto que no se trataba de un producto ni de un método ni de un proceso industrial y que el diagnóstico sobre la novedad de un software respecto de otro, implicaría una organización estatal conformada por técnicos, sumamente costosa y tardía. (Baptiste González, 2017, p. 27).

Si bien son respetables estas opiniones, debe considerarse si es o no pertinente negar la protección del software bajo la figura de la patente, atendiendo solo a razones de índole económico. En efecto, el que resulte costoso acreditar la novedad y la altura inventiva no puede ser razón suficiente para que se desnaturalice su naturaleza jurídica de invención susceptible de la protección debida.

En efecto, de admitirse la viabilidad de otorgar una patente a un software, demandaría de la División de Nuevas Creaciones de la Superintendencia de Industria y Comercio el contar con los medios tecnológicos y el personal especializado para efectuar el análisis pertinente, pero como ya se dejó claro anteriormente, el hecho de que sea dispendioso y costoso el proceso, no incide en que jurídicamente pueda aceptarse esta posibilidad.

Otra discusión no menos importante en torno al tema, tiene que ver con el impacto que tendría para la industria del software, el que se admitiera abiertamente su patentabilidad, ya que 
es obvia la ventaja que tal decisión implicaría para las grandes multinacionales informáticas con la consecuente desventaja para las pequeñas industrias del sector. Esto nos lleva a mirar el tema desde otra óptica, como lo es la función social de la propiedad, principio constitucional del que se impregna todo el ordenamiento colombiano desde la Constitución de 1991.

Aguirre Soriano (2013) señala abiertamente que abrir la posibilidad de patentar el software; es decir, permitir su explotación exclusiva por quien reclame su autoría durante el término de protección, afectaría esta función social, pues limitaría el que otros programadores puedan emprender nuevos desarrollos en torno a una misma idea, lo cual no sucede bajo el actual régimen autoral. Dice el autor:

La hipótesis de la patentabilidad del software se constituye como un planteamiento incompatible con la función social de la propiedad, toda vez que dicha función preconiza un equilibrio entre los intereses económicos de los agentes que confluyen en un espacio económico, en cuanto a que tales múltiples intereses comprendidos como libre competencia, consumo, derecho a la expresión, acceso a la propiedad, incluida la intelectual, etc. encuadren dentro del engranaje propio de la dinámica del beneficio colectivo.

En este orden de ideas, si un Estado, vía regulación, modifica, adopta o implanta absoluta o parcialmente un régimen de protección de la propiedad intelectual del software, a través de patentes, ataca una forma de cultura verdadera por constituir una barrera para la obtención de protección jurídica de tal obra, puesto que impone al creador el requisito de superar el actual estado de la técnica, de la ciencia y de las fuerzas de la naturaleza y ya no solamente le baste cumplir con el requisito de originalidad, generando un considerable lucro cesante en el beneficio común, producto del directo desincentivo a crear para los programadores y demás actuales y futuros talentos que confluyen en el desarrollo de los programas de ordenador, por traducirse en graves repercusiones patrimoniales y morales para estos, toda vez que les imposibilita el acceso a la propiedad intelectual de un activo inmaterial de su creación y así mismo, como efecto colateral, le mengua su derecho a la expresión susceptible de ser apropiable, ocasionando el estancamiento de la indispensable evolución del estado del arte en materia de ingeniería de software. (Aguirre Soriano, 2013, pp.18 y 23).

Ya con anterioridad, había planteado el mismo autor sobre el tema:

De esta circunstancia surge la necesidad de analizar y presentar una mirada, sobre si los efectos de la hipótesis de la patentabilidad del software son positivos o negativos en el contexto global, regional y local, para el caso de Estados Unidos de Norteamérica, la Unión Europea y el caso colombiano en dos aspectos coyunturales de la economía nacional; la libre competencia y el empleo del recurso humano nacional. Dejando como consecuencia una consolidación de prácticas monopolísticas restrictivas de la competencia y un decrecimiento en la generación de empleo en Colombia, así como la pérdida de los ya existentes. (Aguirre Soriano, 2011, p. 1). 
Para un país como Colombia, donde la industria del software es incipiente ${ }^{1}$, si se compara con las cifras de inversión en el sector de países desarrollados y se concentra en pequeñas pymes productoras de videojuegos, el tema es trascendental y merece un estudio serio y extenso sobre las implicaciones económicas que tendría el que se permitiera la patentabilidad de este tipo de creaciones, la que hasta el momento se ha excluido con fundamento en la prohibición contenida en la Decisión 486 del 2000.

No obstante, este trabajo no pretende abarcar un estudio de esta naturaleza. Se limitará a una mirada netamente jurídica a la luz de las normas vigentes en Colombia y la forma cómo vienen siendo aplicadas por las autoridades competentes.

\section{4. ¿Se requiere un régimen suigéneris de protección?}

Se aboga igualmente, por la adopción de un régimen suigéneris de protección para el software. Encontramos la opinión en este sentido de Sarmiento (2016), quién ha planteado la conveniencia de adoptar una normativa especial para el caso del software que garantice la totalidad de derechos involucrados y que implique para los países del esquema de integración, el dar cumplimiento a las obligaciones internacionales adquiridas, por lo cual propone sustituir las normas pertinentes de las decisiones 351 de 1993 y 486 del 2000 por esta nueva normativa.

Acuña et al. hacen referencia a esta serie de iniciativas que abogan por la adopción de un régimen especial:

En la actualidad hay una innumerable cantidad de proyectos tendientes a imponer un sistema de protección de los derechos intelectuales de los creadores de programas de computación distinto al régimen de patentes y al del derecho de autor que contemple las particularísimas características que presentan los programas. Sin embargo, estos proyectos no han recibido hasta la fecha consagración legislativa.

Se busca elaborar un régimen propio destinado exclusivamente a brindar resguardo jurídico a los programas mediante una normativa específica que contemple aquellas características propias de los programas y que no se encuentren presentes en las otras obras que son objeto de protección por aquellos sistemas. (Acuña et al., 2013, p. 39).

Preinfalk también se pronuncia sobre la conveniencia de este régimen especial de protección:

Sin embargo, aunque nosotros sostengamos que el derecho de autor es la rama del ordenamiento que le corresponde tutelar a los programas de ordenador, con una visión hacia futuro, desde un punto de vista técnico, no nos negamos la posibilidad de que se perfile un sistema de protección específica, donde se subsanen las carencias que presenta el derecho de autor en la protección de este objeto y se adapte perfectamente, en el que incluso no sería necesario sustraer el derecho moral de

\footnotetext{
${ }^{1}$ En concepto de Fedesoft, la industria está lejos de ser incipiente pese a que la mayoría de empresas que se ocupan de este negocio han sido creadas en los últimos cinco años. Según registra la Federación, Estados Unidos es uno de sus destinos externos más importantes, aunque es también de resaltar que algunas empresas norteamericanas buscan abrir sus oficinas en el país, dado que la mano de obra es más barata. (Revista Portafolio de mayo 21 de 2018).
} 
autor, aunque su contenido pueda ser modalizado en función del objeto y los intereses de los sujetos involucrados. (Preinfalk, 2010, p. 160).

Existen planteamientos más progresistas, como el formulado por Sol Beatriz Calle D'Alemán (2012), quién luego de cuestionar el actual régimen y descartar igualmente la posibilidad de que se adopte como mecanismo de protección la concesión de patentes, propugna excluir los bienes informáticos como el software del campo de la propiedad intelectual, para someterlos a un régimen especial considerándolos como una nueva categoría de bienes y sujetos, por tanto a un tratamiento sui géneris. Dice la autora:

La otra alternativa que queda es pensar por fuera de lo evidente y, como se plantea en este trabajo, ello supone excluir las herramientas intangibles informáticas de la propiedad intelectual, lo que implica romper paradigmas profundos, posiciones internacionales reiteradas y la proposición de un escenario más amplio, de realidades inmateriales que van más allá de las creaciones del intelecto y que parten de la concepción misma de los bienes incorporales, de la propiedad inmaterial (no solo intelectual) y de la posibilidad de analizarlos como objetos de relaciones jurídicas que no necesariamente deben estar ancladas en la propiedad intelectual. (Calle D'Alemán, 2012, p. 308).

Comparto plenamente las razones que exponen los investigadores mencionados y sin duda la solución que proponen dejaría de lado las múltiples problemáticas que la actual situación plantea, pero no es algo fácil de implementar, puesto que como bien lo señala, la adopción de esta nueva normativa implica derogar disposiciones andinas, lo cual no se considera factible en un futuro próximo, aun cuando hubiera consenso sobre el particular entre los países miembros.

Por otra parte, no debe olvidarse que el Acuerdo ADPIC ratifica que los programas de ordenador se asimilan a obras literarias para su protección por la legislación autoral, además que admite la concesión de una patente para invenciones que pertenezcan a cualquier campo de la tecnología, lo cual nos deja ante la disyuntiva de cómo adoptar en el ámbito andino una regulación que se ocupe específicamente del software sin contrariar los compromisos adquiridos en el acuerdo mencionado.

Pese a lo anterior, una normativa especial podría tomar en consideración la naturaleza específica de este tipo de bien, contemplando una protección integral al mismo, pero teniendo en cuenta además el impacto económico que ello tendría, para racionalizar tanto el tiempo de protección como los derechos que se reconocen a los desarrolladores y titulares de derechos sobre el mismo, a fin de que no se obstaculice el avance en este campo tecnológico.

Dada entonces su conveniencia, se considera pertinente que la Comunidad Andina de Naciones (CAN), como esquema de integración, formule al interior de la Organización Mundial del Comercio (OMC) una propuesta de modificación al ADPIC que autorice a los países miembros la adopción de una normativa especial para este tipo de bienes.

Lo anterior no es extraño, puesto que ya existe un antecedente. En efecto, el 23 de enero de 2017 entró en vigencia una enmienda al Acuerdo sobre los ADPIC, que tiene por objeto 
proporcionar a los países en desarrollo el acceso a ciertos medicamentos. Según se lee en la página oficial de la $\mathrm{OMC}^{2}$, los Estados miembros decidieron modificar el Acuerdo en mención para adaptar las normas que regulan el sistema mundial de comercio, a las necesidades de salud pública de los países pobres.

En apoyo a lo antes dicho, no debe olvidarse que en los inicios del software como bien independiente, ya se había pensado en una regulación especial para el mismo, la que finalmente fue descartada para adoptar las normas del derecho de autor como las más convenientes, por las razones que expone Baptiste González:

Ahora bien, los modelos de protección que el DPI ha construido para el software, han sido álgidamente debatidos por la doctrina de este sector, desde que el problema se planteó en las Cortes norteamericanas en la segunda mitad del siglo xx. Ghidini (2010) relata cómo la madurez del fenómeno tecnológico-económico en Estados Unidos, aunada al creciente desarrollo y comercialización del software como un producto independiente del hardware, dieron origen a la demanda de una protección exclusiva para el primero, que superara la ofrecida por los acuerdos particulares de no competencia y confidencialidad. Así, desde la década del 60, en Norteamérica se discutió si la tutela a este tipo de intangibles debía ser proporcionada a través del sistema del derecho de autor - copyrighto de las patentes. En breve, el derecho de autor - PI- es el derecho del creador de una obra original de contenido artístico, científico o literario sobre dicha creación, que le otorga prerrogativas morales y patrimoniales sobre la misma, mientras que la patente - propiedad industrial - es un monopolio temporal que un Estado garantiza al mismo autor por la creación de un nuevo producto, proceso industrial, mejora de alguno de los anteriores o, en general, innovaciones que tengan aplicación industrial. En el primer caso, los soportes lógicos gozarían de una protección exclusiva de larga duración, menos selectiva, menos costosa y completamente cerrada a la intervención de terceros, incluso para la actualización de los programas protegidos, que además de proteger al autor, se extendería a firmas y profesionales que estuvieran relacionados con la difusión de creaciones intelectuales reproducibles a escala industrial (Ghidini, 2010). Por oposición, si el software fuese amparado por la patente de invención, el Estado otorgaría al creador un derecho exclusivo en virtud de un 'acto de creación encaminado a solucionar un problema técnico que [fuera] nuevo, [tuviera] actividad inventiva y [poseyera] una aplicación industrial' (Guerrero, 2007). En este último escenario, el inventor del programa tendría la carga de acreditar los requisitos adicionales que supone la patente, entre los cuales se destaca el verdadero valor innovador de la creación. (Baptiste González, 2017, pp. 26-27).

Así las cosas, si bien no es un camino fácil, tampoco es imposible formular una iniciativa tendiente a que se adopte una regulación sui géneris que regule el software como bien inmaterial con características específicas, sin que sea necesario forzar su adecuación a los bienes ya regulados.

Como consecuencia de lo anterior, se haría necesario además que se creara un organismo especial, dotado de todas las especificaciones técnicas requeridas que se encargue del reconocimiento de los derechos sobre este tipo de bienes. En efecto, el actual esquema administrativo

${ }^{2}$ Ver página oficial omc (2017). 
no cuenta con los requerimientos para llevar a cabo el examen especial que este tipo de bien requiere. Ni la Dirección Nacional de Derechos de Autor, ni la Superintendencia de Industria y Comercio (sIC) cuentan con el personal, equipo y elementos necesarios para ello.

De ahí que surja la necesidad de admitir abiertamente que este tipo de bienes responde a características especiales y por ende demanda un tratamiento especial, como ocurre a título de ejemplo con las nuevas variedades vegetales.

En efecto, el certificado de obtentor reconoce a su titular el derecho a una explotación exclusiva, en lo que se asimila a una patente, pero no por ello se dejó en manos de la sic su reconocimiento. Al aceptar que se trata de derechos de índole especial, siguiendo los lineamientos del ADPIC, se expidió una normatividad específica, pero al mismo tiempo se entregó el manejo del registro de tales derechos a una autoridad especializada, que además cuenta con los recursos necesarios para realizar este tipo de examen.

En efecto, sobre la naturaleza especial de este tipo de bienes inmateriales y su necesidad de una protección sui géneris se lee a Arcadia Hernández, quien al respecto señala:

\begin{abstract}
Ahora bien, y por lo que respecta al tema de nuestro estudio, el régimen jurídico de protección de variedades vegetales, podemos decir que - en general- es relativamente reciente, si se lo compara con la larga evolución del sistema de patentes. Este hecho obedece a que los procesos científicos de obtención vegetal comenzaron a desarrollarse a partir del redescubrimiento de las leyes de la herencia a comienzos del siglo xx. Desde entonces la necesidad de protección jurídica de las obtenciones vegetales se basó en lo dilatado del proceso de producción de una nueva variedad, que puede llevar de diez a veinte años. Los derechos de obtención vegetal son un tipo de protección especial, adoptada en las legislaciones nacionales a mediados del siglo pasado y regulada a nivel mundial por el cupov. Este sistema se adapta a las necesidades de los obtentores tradicionales que, mediante una serie de cruces entre variedades similares, diseñan una variedad que presenta determinadas características valiosas de los ascendientes y que además es estable y homogénea. Esta clase de actividad, que claramente contiene la intervención de expertos en la materia, es más una innovación que una invención, siendo esta última, objeto del sistema de patentes. (Arcadia Hernández, 2015, pp. 90 y 93).
\end{abstract}

Ahora bien, al ser un bien especial, su sistema de protección también debe serlo, por lo que, en el ámbito internacional, en 1961 se suscribió el Convenio Internacional para la Protección de Obtenciones Vegetales, upov (Unión Internacional para la Protección de las Obtenciones Vegetales). Mediante este convenio, los países pertenecientes se obligaron a adaptar su legislación a los lineamientos señalados en el mismo, y a crear una autoridad nacional en la materia, encargada de hacer efectiva esta protección.

Para Colombia y los restantes países andinos, que hacen parte del Convenio, se expidió la Decisión Andina 345 de 1993, sobre Protección a los Derechos de los Obtentores Vegetales, y a través de esta, la protección se otorga por medio de certificados de obtentor, no de patentes. Así 
mismo, para Colombia, el Instituto Colombiano Agropecuario (ICA), es la autoridad nacional competente, para otorgar los certificados de obtentor.

Para el caso de software, bien podría pensarse en crear una unidad administrativa especial adscrita al Ministerio de Tecnologías de la Información y las Comunicaciones, o incluso en la descentralización por colaboración y asignarse a un ente privado el control sobre este registro público y en tal eventualidad, la llamada a cumplir con esta función, sería la Federación Colombiana de la Industria del Software y Tecnologías Informáticas Relacionadas (Fedesoft), que con sus treinta años de experiencia podría asumir con propiedad este compromiso, todo bajo la directa vigilancia y control del Ministerio antes mencionado.

Debe aclararse, no obstante, que hasta que no se expida la normativa especial para regular el software, la entidad especial a la cual se asigne la función de su registro, tendrá que basarse en las normas ya existentes; esto es, la Decisión 351 de 1993 y la Decisión 486 de 2000, interpretada armónicamente con las disposiciones del ADPIC, como se ha propuesto anteriormente.

\section{Conclusiones}

La segunda mitad del siglo xx se caracterizó por grandes adelantos tecnológicos, como la invención de la computadora y el internet. El derecho, como siempre ha sucedido, se vio en la necesidad de regular lo concerniente a estos nuevos bienes y en cuanto a su protección se pensó en un primer momento que el camino a seguir era la propiedad industrial.

No obstante, una vez el software fue deslindado del hardware surge la discusión sobre la mejor forma de proteger los derechos de sus desarrolladores. Si bien en un principio se pensó que era un bien de naturaleza especial y por tanto requería igualmente una regulación específica, finalmente el consenso general en torno al tema se decantó por los derechos de autor como la forma de protección adecuada, al asimilar el software a una creación literaria, dado que se exterioriza en un lenguaje que si bien es técnico, responde a los mismos principios de toda lengua, abarcando incluso en este concepto el llamado código objeto, que se expresa en un lenguaje binario, entendible solo por una computadora.

Pese a lo anterior, desde sus inicios han surgido voces disidentes en cuanto al camino que se adoptó, al considerar que el software no está compuesto solamente por el código fuente y el código objeto. Por el contrario, lo integran otra serie de elementos que no encajan dentro del concepto de creación literaria, lo cual lleva a que se declare que esta protección no es integral y por ende se reclame la concesión de una patente para este tipo de bienes, como ya viene sucediendo en algunos Estados.

La protección bajo el régimen de patentes también genera una serie de críticas basadas en su mayoría, por el mayor costo que genera para que futuros desarrollos puedan ser emprendidos.

Esta discusión que se ha mantenido durante casi medio siglo, lleva a reafirmar la idea de que ninguna de las formas de protección existentes es idónea por sí sola para proteger de 
manera integral este tipo de bienes, y a partir de este convencimiento ha surgido un tercer camino que no es otro que el pensado en sus inicios; es decir, una regulación sui géneris para esta clase especial de bienes, que además tome en consideración todos los aspectos que implica su uso y explotación.

Se reconoce, no obstante, que lo anterior no es fácil, puesto que implica en primer lugar, modificar acuerdos multilaterales como el ADPIC, que contempla como forma de protección los derechos de autor, sin descartar la concesión de una patente, cuando declara que estas deben ser concedidas sin discriminar el campo tecnológico de que se trate. Así las cosas, la primera discusión sobre el particular debe darse en el seno de la OMC, para luego de que se autorice esta reglamentación especial, la misma pueda ser adoptada por los países integrantes, a nivel de su legislación interna.

En consecuencia, hasta que lo anterior no sea una realidad, si es que llega a serlo, debe garantizarse la protección de este tipo de bienes en el marco de la regulación vigente.

En Colombia, siguiendo los lineamientos del ADPIC, se protege el software bajo la regulación del derecho de autor, señalando además la Decisión 486 de 2000 que no puede ser considerada una invención, por lo que cierra la puerta a que el mismo sea cobijado con una patente.

No obstante, en otro trabajo sobre el tema, se ha sostenido que esta disposición debe interpretarse armónicamente con el acuerdo multilateral que, como ya se expuso, descarta toda discriminación en cuanto a las patentes. Esta interpretación llevaría a que los operadores jurídicos, al entender la norma de la Decisión 486 que excluye el software del concepto de invención, deben concebir que esta exclusión solo opera cuando el software no reúna las condiciones señaladas para la concesión de una patente, ya que en caso contrario, nada impide que esta le sea concedida, admitiéndose entonces una doble protección, bajo las normas del derecho de autor cuando no sea novedoso, no tenga altura inventiva ni sea susceptible de aplicación industrial, o bajo los dos regímenes, derechos de autor y patentes, cuando reúna los presupuestos antes señalados.

En este artículo hemos sostenido, no obstante, que bajo el panorama anterior, es decir, la doble protección, no debe olvidarse que estamos ante un bien de unas características muy propias y por ende se hace necesario que no se someta al tratamiento que se da a otras invenciones. Por el contrario, se hace imperativo crear un organismo especial, dotado de todos los elementos técnicos necesarios, encargado del reconocimiento de los derechos sobre este tipo de bienes, como también sucede con respecto a las nuevas variedades vegetales, a las cuales se les ha dado un tratamiento especial.

Este nuevo órgano debería estar adscrito al Ministerio de Tecnologías de la Información y las Comunicaciones o, incluso, se propone utilizar la figura de la descentralización por colaboración, encargando a un ente privado la administración de este tipo de registro bajo la directa vigilancia y control del Ministerio antes señalado. Se ha propuesto igualmente que este ente privado, perfectamente puede ser la Federación de Colombiana de la Industria del Software 
y Tecnologías Informáticas Relacionadas (Fedesoft), ya que cuenta entre sus asociados con el personal idóneo para esta verificación y puede acceder a los recursos técnicos necesarios para esta función.

\section{Referencias}

Acuña, D. C., Manrique, P. V., Glogower, D., Pasuy, B., \& Peña Valenzuela, D. (2013). Software libre y software propietario: Impacto jurídico, económico y cultural en Colombia. Bogotá, Colombia: Universidad Externado de Colombia.

Aguirre Soriano, D.A. (2011). El posible impacto de la patentabilidad del software en la economía colombiana. Revista de Derecho, Comunicaciones y Nuevas tecnologías, (6), 1-27. Recuperado de https:// dialnet.unirioja.es/servlet/articulo?codigo $=7507215$

Aguirre Soriano, D.A. (2013). La patentabilidad del software y la función social de la propiedad. Revista de Derecho, Comunicaciones y Nuevas tecnologías, (10), 1-28. Recuperado de https://derechoytics. uniandes.edu.co/components/com_revista/archivos/derechoytics/ytics136.pdf

Álvarez-Cabrera, S. F., \& Reyes-Hernández, K. Y. (2017). Protección Jurídica de los videojuegos a través del derecho de autor. Opinión Jurídica, 16 (31), 155-174. https://doi.org/10.22395/ojum.v16n31a7

Arcadia Hernández, C.E. (2015). El régimen de protección jurídica de las obtenciones vegetales en México: Propuestas para una mejor adaptación al sistema cupov. La Propiedad Inmaterial, (19), 89-112. https://doi.org/10.18601/16571959.n19.05

Arenas-Correa, J.D. (2013). Estrategias de autorregulación de bienes intangibles: El caso del software. Medellín, Colombia: Universidad de Antioquia. Recuperado de http://hdl.handle.net/10495/9811

Baptiste González, M.P. (2017). Tratamiento tributario de las rentas derivadas de software en operaciones con no residentes. Revista Instituto Colombiano de Derecho Tributario, (77), 21-54. Recuperado de http://www.icdt.co/publicaciones/revistas/Revista77/art1/Revista77_art1.pdf

Calle D'Alemán, S. B. (2012). Protección jurídica del software: Crítica a su actual regulación y redefinición de su naturaleza frente al derecho. Bogotá, Colombia: Grupo Editorial Ibáñez.

Carrillo, L. (1990). La protección del software: Un marco conceptual para el Decreto 1360 de junio 23 de 1989. El software y los derechos de autor. Bogotá, Colombia: Dirección Nacional de Derechos de Autor.

Flórez Acero, G.D., \& Sierra Marulanda, O.R. (2017). La singular protección de programas de computador o software por parte de la propiedad intelectual. En Flórez-Acero, G.D., Salazar, S., Durán, M.A., Rodríguez-Flórez, J.C. \& Sierra-Marulanda, O.R. Propiedad intelectual, nuevas tecnologías y derecho del consumo. Reflexiones desde el moderno derecho privado. (pp.31-61). Bogotá, Colombia: Editorial Universidad Católica de Colombia. Recuperado de http://hdl.handle.net/10983/15940

Gamba Segovia, R. A., \& Escobar Mora, c. A. (2013). Protección legal del software en las tecnologías de la información por medio de la propiedad intelectual. Revista de Derecho, Comunicaciones y Nuevas Tecnologías, (9), 1-36. https://doi.org/10.15425/redecom.9.2013.05

Grau-Kuntz, K. (2017). Un ensayo histórico sobre los derechos de autor. Revista Chilena de Derecho y Tecnología, 6 (1), 113-150. https://doi.org/10.5354/0719-2584.2017.45192 
Guadamuz-González, A. (octubre de 2017). La inteligencia artificial y el derecho de autor. Revista de la OMPI, (5), 14-19. Recuperado de https://www.wipo.int/wipo_magazine/es/2017/05/article_0003. html

Guerrero Gaitán, M. (2007). Aspectos globales de patentabilidad de las invenciones implementadas por ordenador. Estado actual y nuevas perspectivas. La Propiedad Inmaterial, (10), 117-147. Recuperado de https://revistas.uexternado.edu.co/index.php/propin/article/view/904

Heredero Higueras, M. (1996). Derechos inmateriales y nuevas tecnologías de la información. Informática $y$ Derecho, (9)11, 245-260. Recuperado de https://dialnet.unirioja.es/servlet/articulo?codigo $=248745$

Herrera Bravo, R. (2011). Algunas obras digitales y su protección jurídica. Recuperado de https:// es.slideshare.net/jucegal/obras-digitales-y-su-proteccion-juridica

Mejía Gómez, H.E. (2011). Protección del software en la Ley 23 de 1982. Recuperado de https://docplayer. es/39752779-Proteccion-del-software-en-la-ley-23-de-1982-henry-esteban-mejia-gomez.html

Mejía Gómez, H. E. (2011). Protección del software en la ley 23 de 1982 (Informe de investigación, Universidad CES). Recuperado de http://hdl.handle.net/10946/1922

Organización Mundial del Comercio (OMC) (2017). Se modifican las normas de la OMC relativas a la propiedad intelectual a fin de facilitar el acceso de los países pobres a medicamentos asequibles. [Noticias]. Recuperado de https://www.wto.org/spanish/news_s/news17_s/trip_23jan17_s.htm

Preinfalk-Lavagni, I. (2010). El derecho moral del autor de programas informáticos. Valencia, España: Tirant lo Blanch.

Ramírez Vélez, S., \& Cano Gutiérrez, E. (2015). La protección legal del software: Dificultades en el sistema actual de protección y alternativas a su regulación. (Monografía para optar al título de abogado, Universidad EAFIT, Medellín, Colombia). Recuperado de http://hdl.handle.net/10784/8287

Revista Portafolio (21 de mayo de 2018). Industria del 'software' crecería 19\% en el 2018. Recuperado de https://www.portafolio.co/negocios/industria-del-software-creceria-19-en-el-2018-517332

Saiz García, C. (2019). Las obras creadas por sistemas de inteligencia artificial y su protección por el derecho de autor. Indret: Revista para el análisis del derecho, (1), 1-45. Recuperado de https://www.raco. cat/index.php/InDret/article/view/354489/

Sarmiento Páez, C. D. (11 de septiembre de 2016). La protección del software desde la propiedad intelectual en Colombia: Conveniencia de la creación de una normativa especial que garantice los derechos de los desarrolladores. Blog del Departamento de Propiedad Intelectual. Bogotá, Colombia: Universidad Externado de Colombia. Recuperado de https://bit.ly/2Hucmrv 